\title{
Governance for Nanotechnology: Definition of Nanomaterials
}

\author{
${ }^{1,2}$ Ricardo Santana, ${ }^{3}$ Robin Zuluaga, ${ }^{4}$ Piedad Gañán \\ ${ }^{1}$ New Materials Group, Bolivarian Pontifical University, Medellín, Colombia. \\ ${ }^{2}$ Deustotech, University of Deusto, Bilbao, España. \\ ${ }^{3}$ Facultad de Ingeniería Agroindustrial, Universidad Pontificia Bolivariana, Circular $1^{\circ} \mathrm{N}^{\circ}$ 70-01, Medellín, \\ Colombia. \\ ${ }^{4}$ Facultad de Ingeniería Química, Universidad Pontificia Bolivariana, Circular $1^{\circ}$ N ${ }^{\circ} 70-01$, Medellín, \\ Colombia.
}

\begin{abstract}
The present work constitutes an approach to nanotechnology from the legal point of view. We present and analyze different definitions of nanomaterial - especially from the European Union and the International Organization for Standardization-. The aim is to assess the relevance of the definition given by the National Advisory Council of the Colombian Network of Nanoscience and Nanotechnology. ${ }^{1-2}$

(NACCNNN) Nanomaterial: "Naturally or artificially synthesized, manufactured or manufactured material that exhibits properties, phenomena or biological effects that are attributable to its dimensions up to a limit scale of a micrometer. In the specific case of nanoparticulate materials, they will have this category when they present a distribution greater than $10 \%$ of particles less than or equal to $100 \mathrm{~nm}$ in at least one of its dimensions. In addition to this classification, materials that have been modified on a nanometric scale in their conformation or interface to give rise to a material with new properties, are included".

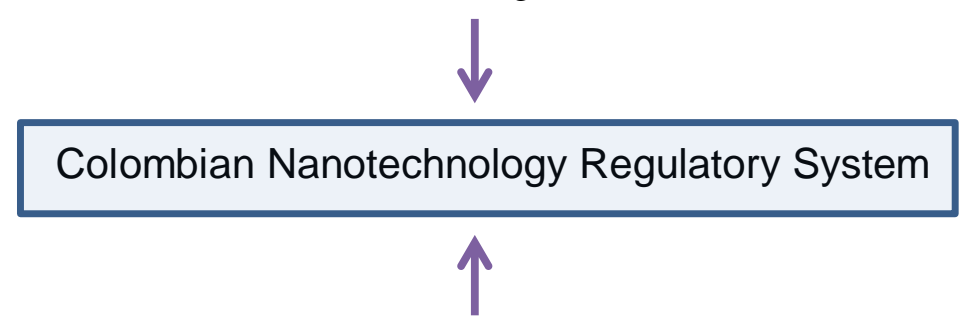

(ISO/TS 80004-1:2015) Nanoobject: "Object that has one, two or three external dimensions in nanoscale".
\end{abstract}

1. Brosset, E. (2013). The law of the European Union on Nanotechnologies: Comments on a paradox. Review of European, Comparative and International Environmental Law, 22(2), 155162.

2. Camacho, A., Duarte, A., Dubay, D., Forero, E., Gónzalez, E., Jaramillo, F., Urquijo, W. (2016). Definición de Nanomateriales para Colombia. Colomb. Quim., 45, 15-20. 